\title{
Simplification of Separation of Reaction Mixture after Transesterification of Vegetable Oil
}

\author{
Martin Hájek, František Skopal, Jaroslav Machek \\ Department of Physical Chemistry, Faculty of Chemical Technology, \\ University of Pardubice, Pardubice, Czech Republic
}

Correspondence: Martin Hájek, Department of Physical Chemistry, Faculty of Chemical Technology, University of Pardubice, nám Čs. legií 565, 53210 Pardubice, Czech Republic. Phone: +420 466037 053, Fax: +420 466037 068; e-mail: martin.hajek2@upce.cz

Keywords: Biodiesel, vegetable oil, sedimentation, water, refractive index 


\section{Summary}

Heterogeneous reaction mixture is formed by transesterification of vegetable oils. The reaction mixture contains methyl esters of higher fatty acids and glycerol mainly. From this mixture, biodiesel is gained by spontaneous sedimentation in the gravitational field. The sedimentation can be considerably accelerated by controlled addition of water. It was found that addition of small amount of water into the crude reaction mixture affected significantly the mixture and substantial change in the speed of the separation took place. Considerable differences in the composition and quality of ester and glycerol phases occurred. Optical properties (transmittance and refractive indices) of heterogeneous reaction mixture are change after addition of water; this change can be observed spectrophotometrically. This method is applicable for all types of vegetable oils including waste frying oils.

\section{Introduction}

Deterioration of environment caused by toxic materials which are produced by expanding automobile transport and increasing prices of crude-oil-based fuels motivate us to search for alternative, environment-friendly sources of energy. Biodiesel is an alternative to conventional diesel fuel for combustion in compression-ignition engines. It is a mixture of methyl esters of higher fatty acids. Biodiesel is a nontoxic ecological fuel, which does not include sulfur nor aromatic components, it is easily biodegradable [1,2] and renewable. Other advantage of biodiesel is that it can be produced by domestic producers. The enhance lubricity of biodiesel in relation to convention diesel fuel is what impart reduced wearing of diesel engines [3]. Low air pollution, high lubricating ability and biodegradability are the main advantages of biodiesel.

All types of vegetable oils including waste oils can be used for biodiesel production. Transesterification using a basic catalyst is the most widely used way of biodiesel production. The most frequent production conditions of the reaction are: temperature $60-80{ }^{\circ} \mathrm{C}$, atmospheric pressure and molar rate alcohol/oil 6:1 [4]. A basic catalyst is used from 0.5 to $1 \%$ of the weight of the vegetable oil. A new attractive way of biofuels production is its obtaining by enzymatic catalyzed alcoholysis of vegetable oils and animal fats [5]. Another developing method of biodiesel production is the preparation of esters by supercritical methanol without catalyst. Methanol can be brought to supercritical stage by high temperature and pressure [6]. Special catalysts of transesterification, based on organometallic complexes of tin and zircon [7] or solid acid catalysts (zeolite) [8] are developed, too.

In this paper, biodiesel was prepared by transesterification of rapeseed oil by methanol and potassium hydroxide was used as the catalyst (1). A heterogeneous crude reaction mixture is formed in the aforementioned reaction. The mixture is composed of two liquid phases - ester (EP) and 
glycerol phase (GP). The excess catalyst is eliminated by gaseous carbon dioxide dosed into the final reaction mixture (2).

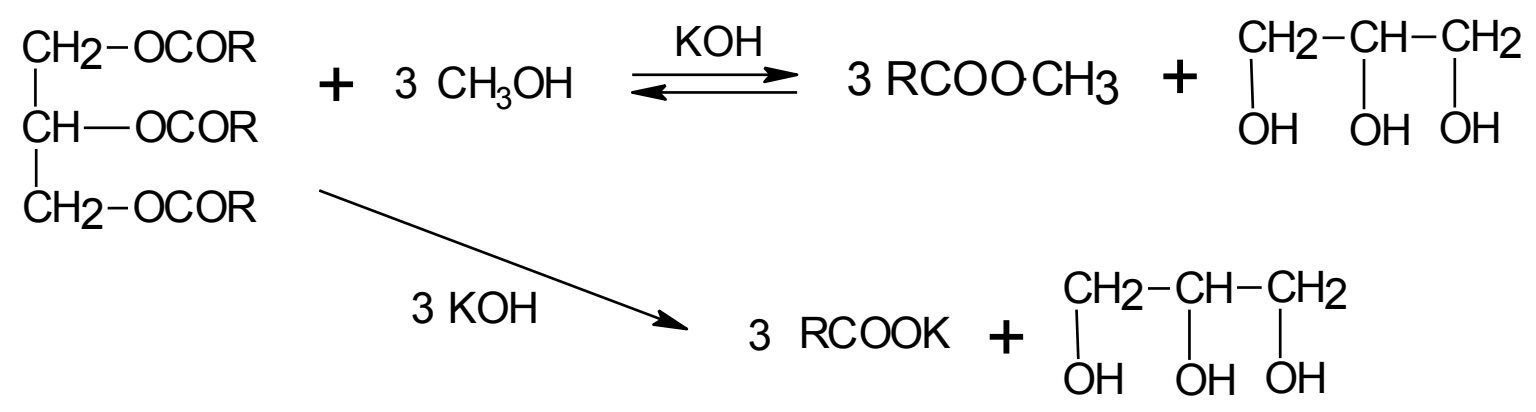

where $\mathrm{R}$ is hydrophobic rest of fatty acids

$$
2 \mathrm{KOH}+\mathrm{CO}_{2} \longrightarrow \mathrm{K}_{2} \mathrm{CO}_{3}+\mathrm{H}_{2} \mathrm{O}
$$

The distillation of methanol from the neutralized reaction mixture is the next step in this procedure. Main products, mixture of methyl esters and glycerol, are separated usually by sedimentation. To accelerate the separation, suitable amount demineralized water is added into the mixture [9]. The heavier glycerol phase (GP) contains, besides glycerol, also the rest of the catalyst in the form of potassium carbonate, soaps and some methyl esters. The lighter ester phase (EP) contains methyl esters and unreacted oil, residuals of soaps and glycerol.

No papers focused on the separation course of the reaction mixture after vegetable oils transesterification have been published yet.

\section{Material and methods}

\subsection{Used chemicals}

Rapeseed oil: firm ABC Brancouze, $\mathrm{CZ}$

Potassium hydroxide (solid 83 \%), methanol (technical quality): Lach-Ner, CZ

Demineralized water: water was prepared by reverse osmosis (AQUL 21, Aqual, Czech Republic)

\subsection{Preparation of samples}

Transesterification of rapeseed oil by methanol was carried out by basic catalyst (reaction temperature $60^{\circ} \mathrm{C}$ with $1 \mathrm{wt} \%$ potassium hydroxide and molar ratio of $1: 6$ of the rapeseed oil to methanol) in the batch reactor. The excess of catalyst was eliminated by gaseous carbon dioxide dosed into the reaction mixture after transesterification. Exact procedure of biodiesel preparation is described in the patent [10]. Rapeseed oil was used mostly, but other types of vegetable oils (e.g.: sunflower, palm, used frying oil) were tested, too. Raw reaction mixture (RRM) is formed after transesterification, neutralization of catalyst and demethanolization. Sample of RRM (20-23 g) was dosed to a cuvette in the spectrophotometer apparatus (Fig. 1). The sample was mixed approx. 10 min under constant temperature $\left(20-60^{\circ} \mathrm{C}\right)$ and constant revolutions of the stirrer $(500 \mathrm{rpm})$. A 
chosen amount of demineralized water was added to RRM after standstill value of transmittance. Dependence of the intensity of radiation transmitting through the mixture on the time was recorded. Every addition of water was $0.05 \mathrm{~cm}^{3}$.

\subsection{Monitoring of sedimentation}

Spectrophotometrical observation of separation was carried out in the apparatus depicted in Fig. 1. Spectrophotometer (SPEKOL 11, Carl Zeiss Jena) (A) with temperature measuring attachment (B) for measuring of transmittace is the base of this apparatus. The attachment with cuvette (optical length $2 \mathrm{~cm}$, volume $30 \mathrm{~cm}^{3}$ ) was kept at constant temperature by thermostat (C). Mixture in the cuvette was stirred with glass spiral stirrer (D). Revolutions of stirrer were adjusted by stabilizer of voltage (F) and determined by revolution indicator (DZM-control.m, IKA ${ }^{\circledR}$, Germany). Water was dosaged into cuvette by micro burette $\left(1 \mathrm{~cm}^{3}\right)$. All courses of separation (measured as dependence of transmittance on amount of water) were registered on PC.

$100 \%$ transmittance was set to pure methyl ester on the spectrophotometer. All measurements were carried out with wave length $570 \mathrm{~nm}$. There was the maximum of transmittance of both phases in this wave length, therefore it was chosen for all experiments.

\section{Results and discussion}

Transmittance decreases very fast after every addition of water to RRM and subsequently it increases very fast up to steady state. The other heterogeneous systems were not tested; therefore we do not know whether this process is applicable generally to all liquids or only to RRM.

Transmittance increases up to maximum (point of the maximum clarity) during addition of water into RRM. After the point of the maximum clarity, further amount of water added to RRM causes a decrease of transmittance. The mixture gets turbid immediately after every addition of water (see Fig. 2) and clarity occurs later. Total clarification of the mixture (to the point of the maximum clarity) and following cloudiness (after the point of the maximum clarity) arises during the addition of water. The fastest separation takes place in the maximum of transmittance (which is the minimum of absorbance) after stop of stirring, e.g. in the point of maximum clarity.

The change of transmittance during the additions of water is caused by the change of refractive indices (RI) of glycerol phases. RI of EP is constant for constant temperature and it is independent on additions of water because EP is not miscible with water. Additional water dissolves in GP only and dilutes this phase. Additions of water decrease gradually the refractive index of GP, because water has lower RI than GP. Maximum of transmittance (Fig. 3) is reached when the RI of EP and GP have the same value. Then, after stop of stirring, the fastest separation of EP from GP takes place. RI of GP is further decreased by more additions of water, the mixture becomes turbid, and 
the separation process becomes much slower than when the separation is carried out in the point of the maximum clarity.

Course of separation was monitored after the stoppage of stirrer as the dependence transmission of for reaction mixture vs. time. In Fig. 4 two dependences of transmittance on time are depicted: the curve 1 shows the separation in the point of maximum clarity. Curve 2 one shows the separation without addition of water. The fastest separation (i.e. time of $100 \%$ transmission) occurs in the point of maximum clarity; the course without water is much slower. Almost the same clarity of biodiesel as pure biodiesel has (100\% transmittance) is reached after 20 min, when water is added. When no water is added, the same clarity occurs after 16 hours, $75 \%$ of the pure biodiesel transmittance was reached after 7 hours.

Refractive indices (RI) are dependent on temperature; therefore the amount of water added during the separation depends on temperature, too. RI of both phases decrease with decreasing temperature, but RI of EP decreases faster than RI of GP. Different rates of decreasing of RI cause increase of optimum amount of added water with decreasing temperature during of the RRM the separation process (Fig. 5).

It was necessary to find out whether addition of water to RRM changes acid value and water content. Therefore, two biodiesel samples were prepared: the first was prepared by addition of water (2.2). The second was prepared on the same conditions of transesterification and demethanolization, but without addition of water. This experiment was reproduced fivefold. The acid value and the water content were determined in EP after separation of GP (Table 1). The methods described in the Euro norm (EN 14214:2003) were used. The acid value of EP was the same in both cases and fulfils the Euro norm, thus addition of water does not change this parameter and does not cause the hydrolysis. Water content in EP is the same in both cases too, but unfortunately does not fill the norm. Therefore, the ester phase must be dried in the next step of production.

\section{Conclusions}

It is possible to accelerate the sedimentation by addition optimum amount of demineralized water after transesterification of vegetable oils (all types of oils can be used), neutralization of excess catalyst and demethanolization. The optimum amount of water is determined by measurement of the transmittance of RRM at $570 \mathrm{~nm}$. The fastest separation of the ester phase from the glycerol phase is reached in the maximum of clarity (maximum of transmittance). The change of transmission of the system is caused by the change of refractive index of GP during the addition of water. Neither acid value nor water content changes, if water is added to RRM. 


\section{Acknowledgements}

This work has been funded by the research project MŠM 0021627502 of the Czech Ministry of Youth and Sport.

\section{Reference}

[1] Yuan-Chung Lin, Wen-Jhy Lee, Tser-Son Wu, Chih-Ta Wang: Comparison of PAH and regulated harmful matter emissions from biodiesel blends and paraffinic fuel blends on engine accumulated mileage test. Fuel. 2006, 85, 17-18.

[2] S. Win Lee, T. Herage, B. Young: Emission reduction potential from the combustion of soy methyl ester fuel blended with petroleum distillate fuel. Fuel. 2004, 83, 11-12.

[3] John W. Goodrum, Daniel P. Keller: Influence of fatty acid methyl esters from hydroxylated vegetable oils on diesel fuel lubricity. Bioresource Technology. 2005, 96, 7.

[4] G. Vicente, M. Martínez, J. Aracil: Integrated biodiesel production: a comparison of different homogeneous catalysts systems. Bioresource Technology. 2004, 92, 3.

[5] M. Oda, M. Kaieda, S. Hama, H. Yamaji, A. Kondo, E. Izumoto, H. Fukuda: Facilitatory effect of immobilized lipase-producing Rhizopus oryzae cells on acyl migration in biodiesel-fuel production. Biochemical Engineering Journal. 2005, 23, 1.

[6] S. Saka, D. Kusdiana: Biodiesel fuel from rapeseed oil as prepared in supercritical methanol. Fuel. 2001, 80, 2.

[7] S. Furuta, H. Matsuhashi, K. Arata: Biodiesel fuel production with solid superacid catalysis in fixed bed reactor under atmospheric pressure. Catalysis Communications. 2004, 5, 12.

[8] S. Kumar Karmee, A. Chadha: Preparation of biodiesel from crude oil of Pongamia pinnata. Bioresource Technology. 2005, 96, 13.

[9] F. Skopal, K. Komers, J. Machek, I. Koropecký, M. Hájek: The Czech Republic patent application PV 2007-267 (2007).

[10] F. Skopal, K. Komers, J. Machek: The Czech Republic patent 289417 (2001). 
Fig. 1: The scheme of the apparatus for monitoring of the separation

Fig. 2: The course of addition of water to RRM (constant temperature $30{ }^{\circ} \mathrm{C}$ )

Fig. 3: Change of the refractive indices during the addition of water to RRM $\left(30^{\circ} \mathrm{C}\right)$

Fig. 4: Course of separation after stoppage of the stirrer

Fig. 5: Dependence of the point of the maximum clarity on temperature 
Fig. 1, Martin Hájek

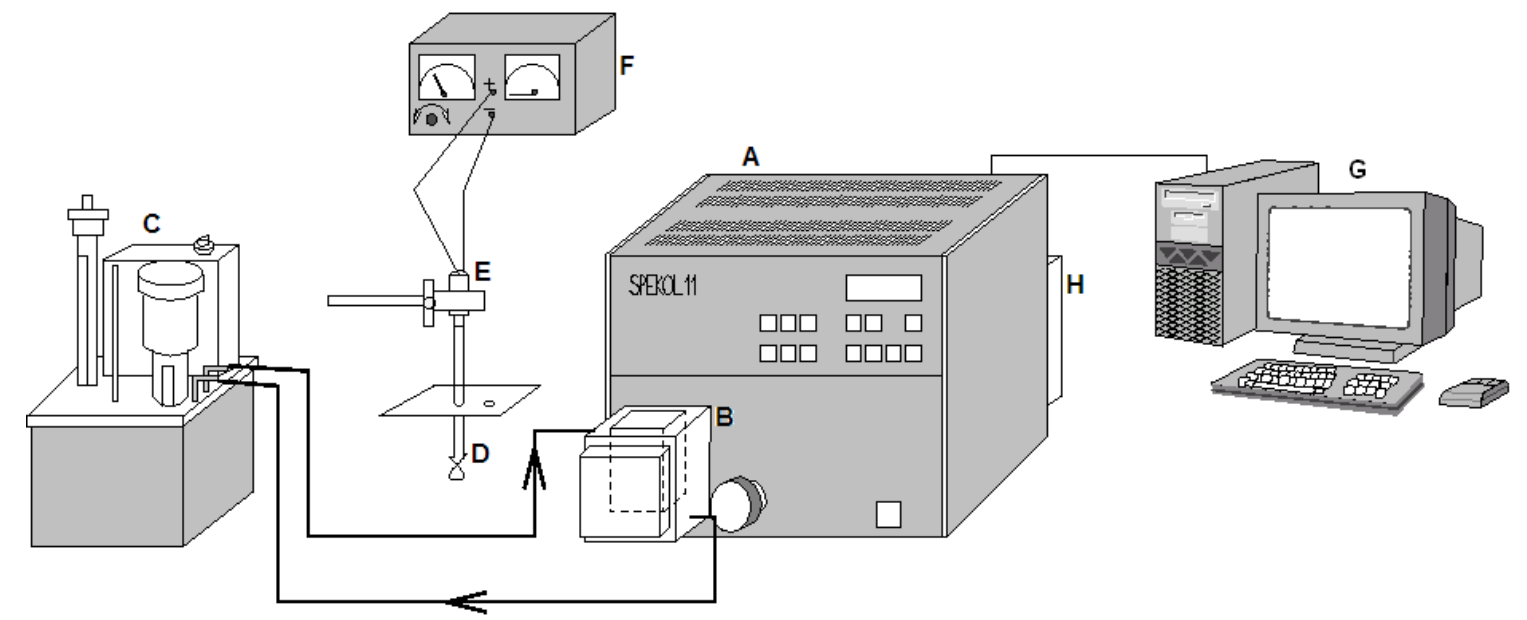
A - spectrophotometer SPEKOL 11
E - electric motor
$\mathrm{B}$ - termostating equipment with a cuvette
$\mathrm{F}$ - stabilizer of voltage
$\mathrm{C}$ - thermostat
$\mathrm{H}$ - radiation source
D - glass stirrer
G- PC 
Fig. 2, Martin Hájek

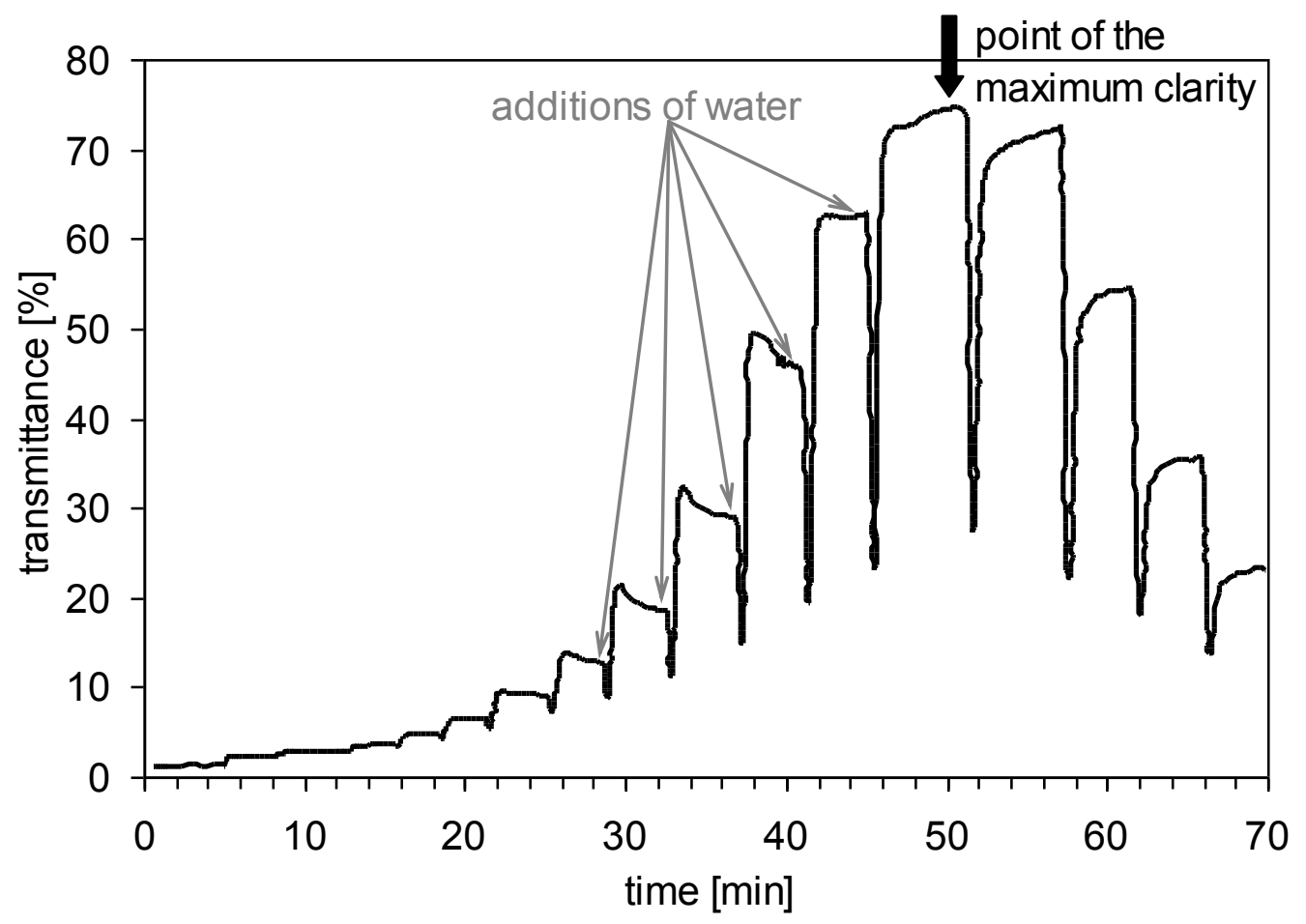


Fig. 3, Martin Hájek

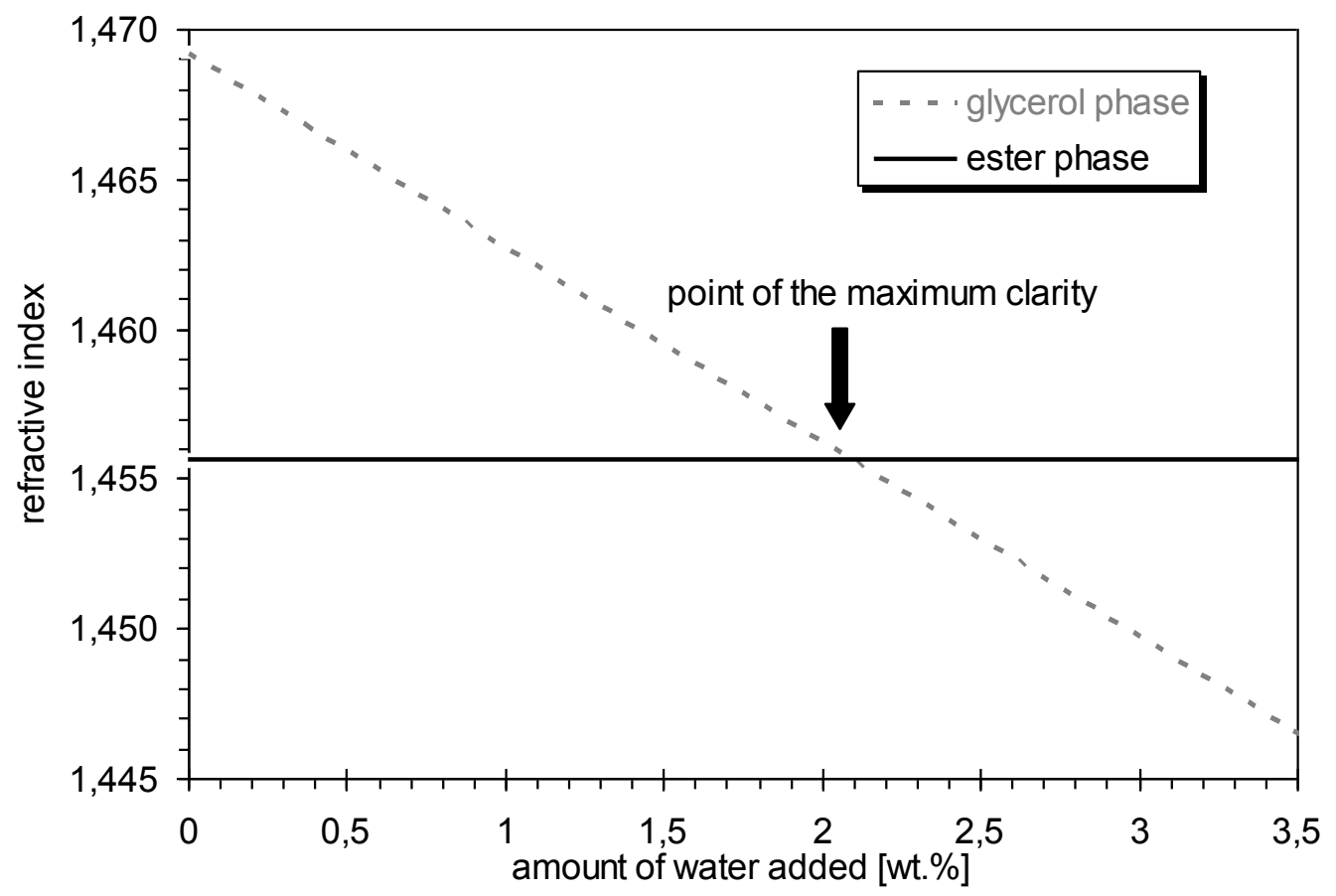


Fig. 4, Martin Hájek

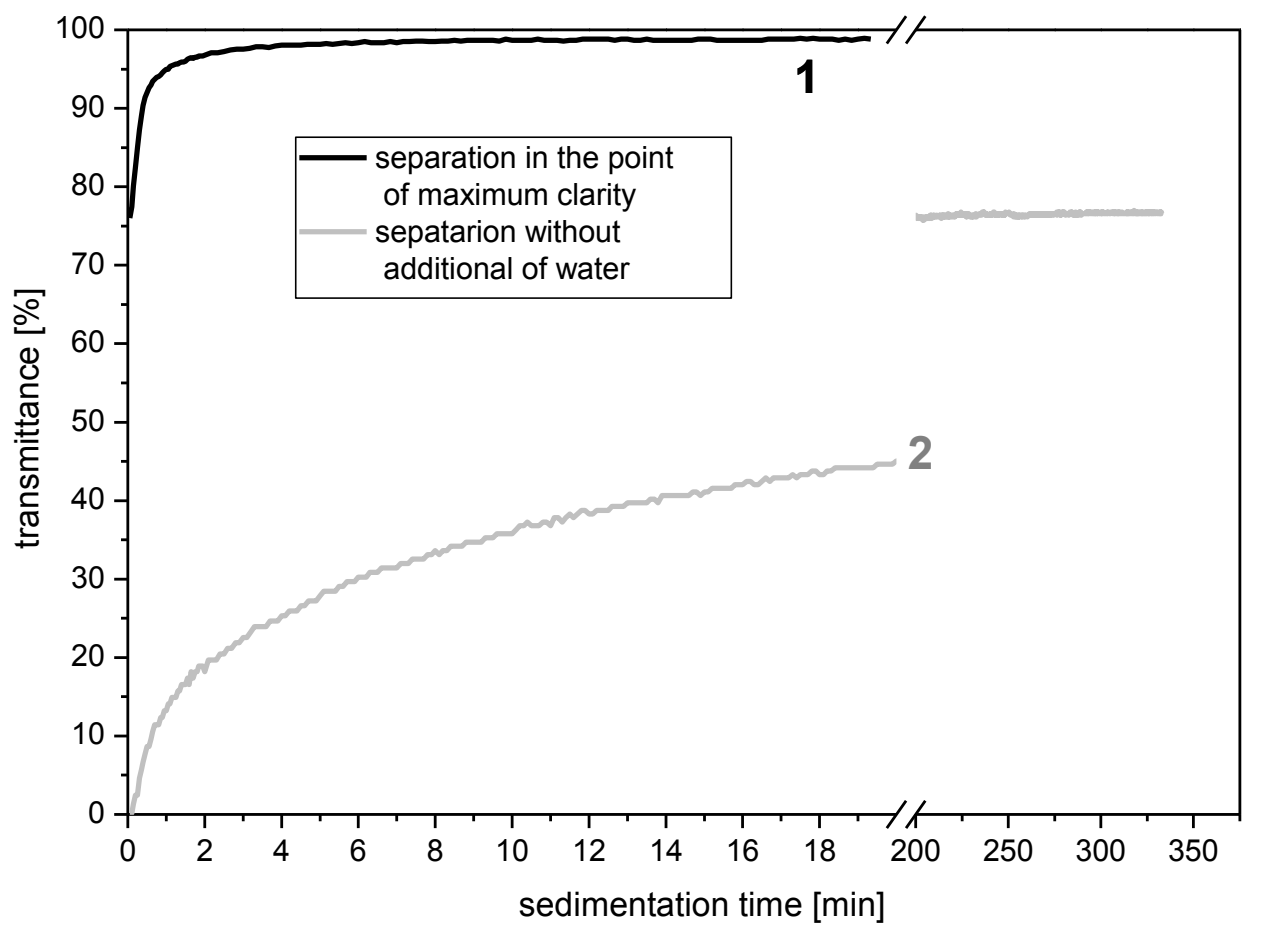


Fig. 5, Martin Hájek

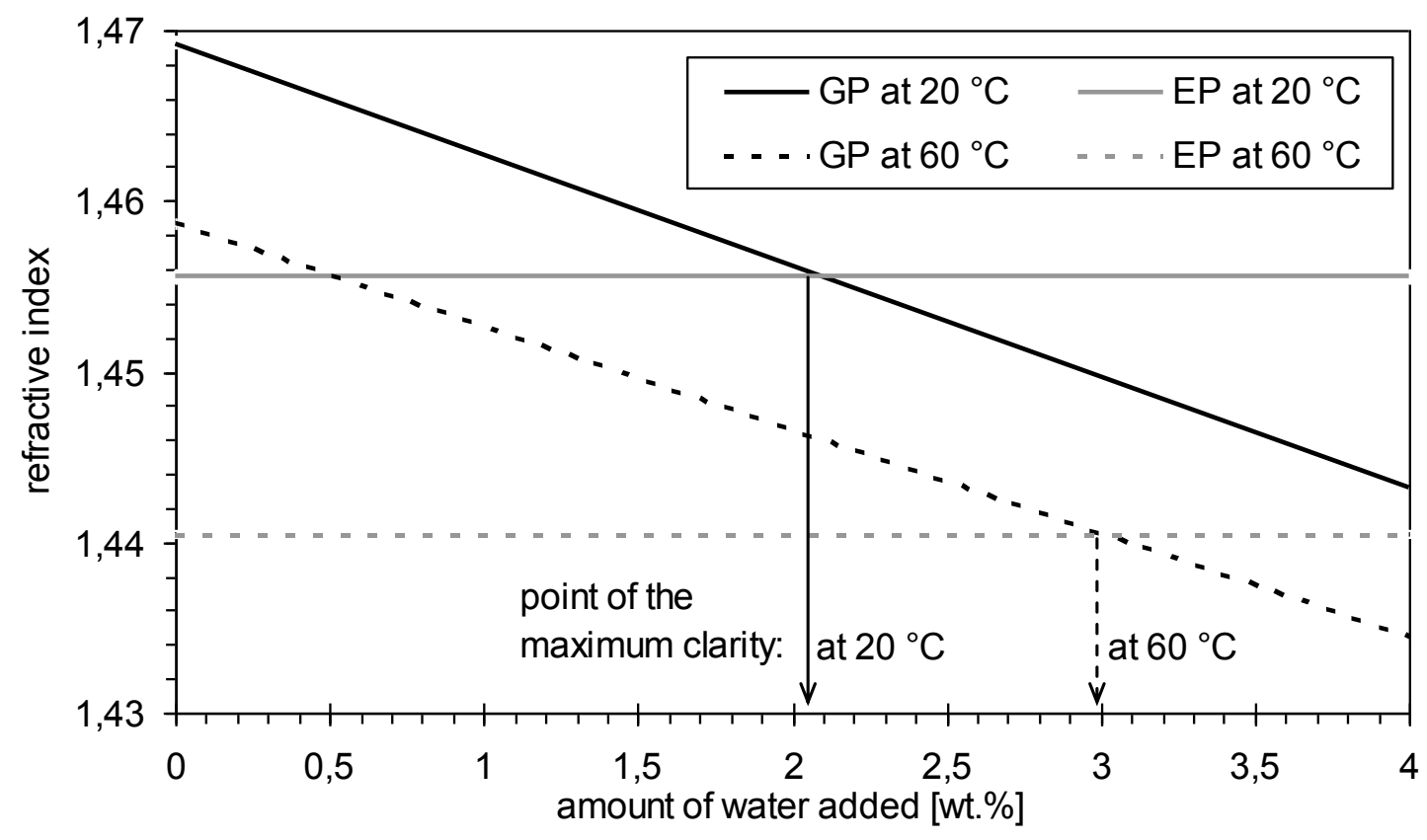


Tab. 1: Comparison of acid value and water content for EP with and without addition of water

\begin{tabular}{ccc}
\hline $\begin{array}{c}\text { Addition } \\
\text { of water }\end{array}$ & $\begin{array}{c}\text { Acid value }[\mathbf{m g} / \mathbf{g}] \\
\text { (norm: } \mathbf{m a x} \mathbf{0 . 5} \mathbf{~ m g} / \mathbf{g} \text { ) }\end{array}$ & $\begin{array}{c}\text { Water content }[\mathbf{p p m}] \\
\text { (norm: } \mathbf{m a x} \mathbf{5 0 0} \mathbf{~ p p m )}\end{array}$ \\
\hline yes & $0.15 \pm 0.03$ & $727 \pm 65$ \\
no & $0.16 \pm 0.02$ & $700 \pm 53$ \\
\hline
\end{tabular}

